\title{
ANÁLISE DA VIABILIDADE ECONÔMICA: UMA ALTERNATIVA DE MATERIAL DE FABRICAÇÃO PARA PISO PODOTÁTIL
}

\author{
Adilson Faustino da Silva Júnior, (UFCG), adilsonfaustino1216@gmail.com \\ Corina de Santana Souza Germino, (UFCG), germino.corina@gmail.com \\ José Higor Melo Júnior, (UFCG), higormelo_@live.com \\ Keren Karolyne Nóbrega Silva, (UFCG), kknstrabalhos@gmail.com
}

\section{Resumo}

A Norma Brasileira Registrada (NBR) 9050:2004 regula os procedimentos na instauração e adaptação de edificações, além de critérios para construção, espaços, mobiliários e dispositivos urbanos às exigências de acessibilidade para a pessoa com deficiência física. Nesse sentido, o objetivo do estudo foi desenvolver um piso tátil economicamente viável, utilizando insumos de baixo custo, como alternativa de produto para o mercado. Para tanto, foram realizadas as etapas de avaliação inicial do produto, projeto e desenvolvimento, e o detalhamento do processo. O produto final atendeu o objetivo proposto no trabalho, bem como os requisitos da norma técnica supracitada.

Palavras-chave: Piso tátil; Acessibilidade; Ergonomia; Fabricação.

\section{Introdução}

É crescente a adesão aos conceitos de acessibilidade no Brasil. Esse progresso se dá aos esforços dos profissionais de diversas áreas, que pensam em formas de melhorar o produto no mercado atual ou inovar o mesmo de forma economicamente viável, utilizando as normas técnicas e as leis que visam a utilização do espaço por todas as pessoas (ALMEIDA et al, 2013).

A NBR 9050:2015 define a acessibilidade como possibilidade e condição de alcance, entendimento e percepção de utilização, com segurança e autonomia, de todo espaço público ou privado, rural ou urbano, para pessoas com deficiência ou mobilidade reduzida. 
Desse modo, a ausência da acessibilidade distancia as pessoas da convivência social. Contudo, as restrições de alguns indivíduos se devem a carência do ambiente não abranger as diversidades, tendo em vista que a má adequação do espaço, limita as pessoas com deficiência. Tendo isto, alguns locais apresentam inadequações, que por sua vez, interfere na locomoção, como também impede a movimentação segura e independente deste indivíduo. (BITTENCOURT et al, 2008)

Para as pessoas que possuem uma boa visão, é possível a visualização de todos os obstáculos prováveis, mas para as pessoas com deficiência visual, é improvável. Com isso, os mesmos possuem algumas características aprimoradas, como por exemplo a audição seletiva e o tato exploratório, que ajudam em um movimento orientado.

Conforme Dischinger e Bins Ely (1999), o tato exploratório é uma forma do indivíduo identificar objetos, formas, relevo e texturas utilizando o corpo, as mãos e a bengala. Em decorrência do movimento orientado, a pessoa com deficiência visual obtém uma informação constante do espaço onde se encontra, de acordo com seu eixo de referência, sendo horizontal ou vertical, direita ou esquerda, como também a direção e movimentos contínuos.

Deste modo, segundo a NBR 9050, o piso tátil entra com o objetivo de resolver alguns problemas de locomoção, servindo de orientação para esses indivíduos com a deficiência citada ou até mesmo para aqueles de baixa visão. O mesmo é caracterizado pela utilização de texturas, entre elas as linhas contínuas (linha-guia), que servem para indicar um movimento constante e as de alerta, que passa uma informação de atenção para o usuário. Entre outras características, esse piso deve conter também uma cor com alto contraste em relação ao piso normal.

Nesse contexto, o objetivo do estudo foi desenvolver um piso tátil economicamente viável, utilizando insumos de baixo custo, como alternativa de produto para o mercado. A matéria-prima barata permite que o produto tenha um preço competitivo, além do fácil acesso aos materiais de produção.

\section{Referencial Teórico}

\subsection{Ergonomia}


A ergonomia trata da interação entre o homem e o trabalho, e das relações ocasionadas na execução da ocupação, englobando as ações antes, durante e depois da realização do trabalho. O objeto de estudo da ergonomia é a adaptação do posto de trabalho ao operário, além, de como se dá o relacionamento entre o funcionário e a atividade produtiva (IIDA, 2005).

De acordo com Iida (2005), toda atividade produtiva traz algum resultado prejudicial ao homem, por exemplo, estresse, fadiga e até mesmo acidentes. Em decorrência disso, a ergonomia tem como principal objetivo mitigar esses fatores nocivos à saúde do operário, proporcionando bem-estar na realização do trabalho, e por consequência menor degradação da capacidade produtiva do trabalhador.

\subsection{Ergonomia e acessibilidade}

A adaptação do trabalho a grande parte dos trabalhadores é o escopo principal da Ergonomia, entretanto, para inclusão de profissionais com deficiência, algumas adaptações serão necessárias para adequação às particularidades de um funcionário singular, visando o êxito na execução das atividades de trabalho (MÁSCULO, VIDAL, 2011).

Ainda segundo Másculo e Vidal (2011), na visão ergonômica, a deficiência é um distúrbio em algum dos subsistemas neuro-musculoesquelético (N-M-E), resultando na inabilidade de reagir a uma determinada tarefa da mesma maneira que uma pessoa não deficiente. Entretanto, o profissional com deficiência pode realizar tarefas como qualquer outro, mediante condições de trabalho adequadas. Em outros países, algumas indústrias já promovem a inclusão de colaboradores com deficiência no seu quadro de empregados. Para tanto, se faz necessária uma atividade apropriada àquele funcionário, além de treinamento e ajuste dos postos de trabalho, para que estes estejam adaptados aos operários (IIDA, 2005).

No ano de 1991, entrou em vigência a Lei nº8.213 de 24/07/1991, que no artigo 93 estabelece a proporção de cargos para pessoas com deficiências. De $2 \%$ a $4 \%$ para empresas com 100 até 1.000 funcionários, e nos casos das empresas com mais de 1.001 empregados, a porcentagem é de $5 \%$ dos cargos. Em razão dessa determinação, as 
empresas têm que se adaptar cada vez mais a esses indivíduos, além de garantir um posto de trabalho e atividades adequadas, para que se possa atender ao ritmo das atividades.

\subsection{Portadores de deficiências físicas no ambiente de trabalho}

Segundo Iida (2005), a ergonomia física é a área que analisa as particularidades das características humanas, antropometria, anatomia, biomecânica e fisiologia, que se relacionam com as atividades físicas do trabalho. Todos esses aspectos do organismo humano, tem influência na execução das atividades de produção. Inseridos nesse contexto, os portadores de deficiência físicas são uma parcela da população, que por razão médica, acidental ou congênita, possui redução em alguma habilidade física.

De acordo com o Censo Demográfico 2010, feito pelo Instituto Brasileiro De Geografia e Estatística (IBGE), há no Brasil 45.606,048 milhões de pessoas que declararam ter pelo menos uma deficiência, seja ela motora, visual ou auditiva, que representam $23,9 \%$ da população brasileira. Dentre essas pessoas, 38.473,702 residem em áreas urbanas e 7.132,347, nas áreas rurais. O Nordeste reúne os municípios com os maiores percentuais da população com pelo menos um tipo de deficiência, conforme a figura 1.

Figura 1- Percentual de pessoas com pelo menos uma das deficiências no Brasil (2010)

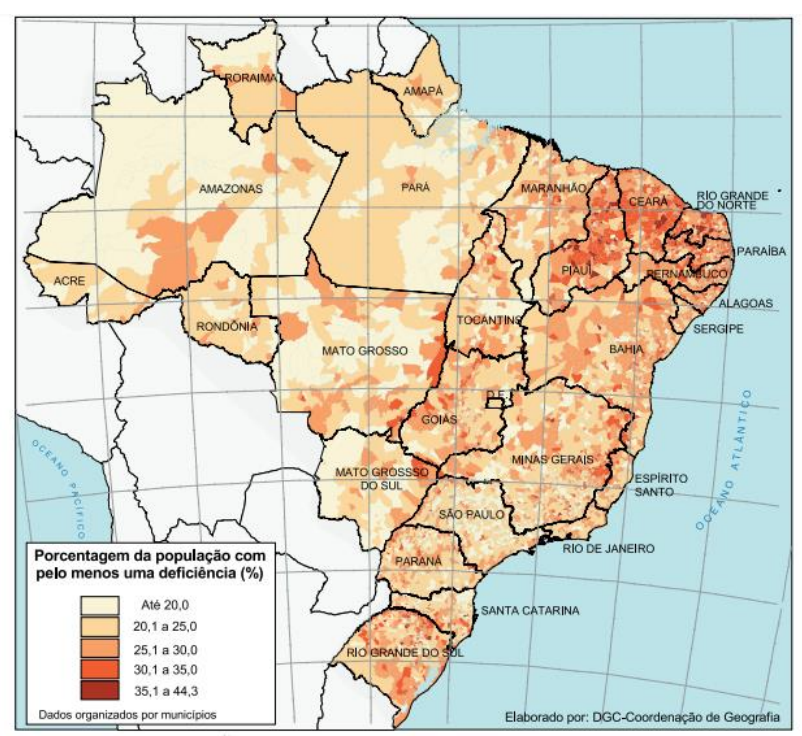

Fonte: IBGE, Censo Demográfico 2010. 
Conforme o IBGE, a condição de deficiência é um aspecto que restringe o processo de admissão no mercado de trabalho, entretanto, observou-se que $40,2 \%$ da população com alguma deficiência possui carteira de trabalho assinada. Porém, a taxa de empregadoras que contratam profissionais com deficiências é de apenas 1,8\%. Isto é, a maior dificuldade para as pessoas portadoras de deficiência é encontrar uma empresa que as contrate, mesmo estas sendo tão concorrentes intelectualmente quando as pessoas não portadoras de deficiência.

\subsection{Piso tátil}

Diariamente, nos locomovemos por diversos ambientes e para diferentes localidades dentro das cidades em que vivemos, essa pode ser uma tarefa simples para alguns, entretanto, uma parcela da população vê nessa atividade cotidiana verdadeiros desafios (ALMEIDA et al, 2018).

Para facilitar a adaptação dos ambientes às particularidades dos portadores de deficiências físicas, a ABNT - Associação Brasileira de Normas Técnicascriou a Norma NBR 9050, que regulamenta os procedimentos na instauração e adaptação de edificações, além de critérios para construção, espaços, mobiliários e dispositivos urbanos às exigências de acessibilidade para a pessoa com deficiência física (ABNT, 2004).

Figura 2: Espaço para locomoção em um caminho retilíneo (a) apenas um indivíduo em uma cadeira de rodas (b) um indivíduo cadeirante e uma pessoa sem deficiência física(c) dois indivíduos locomovendo-se com o auxílio de suas cadeiras condutoras.

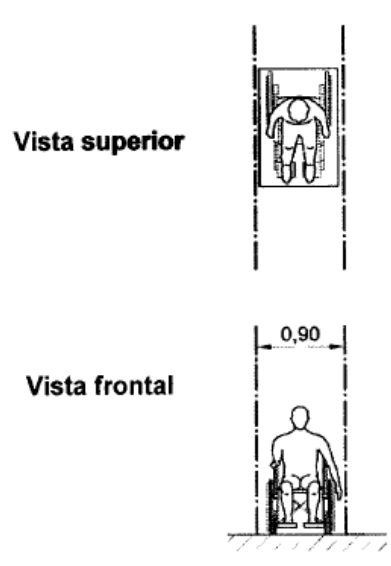

(a)
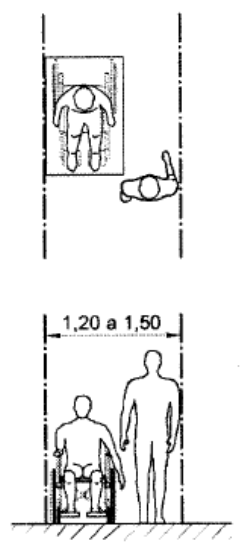

(b)
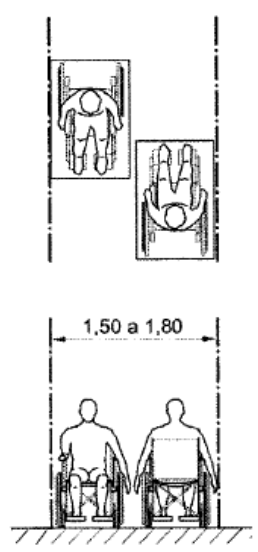

(c)

Fonte:ABNT NBR 9050:2004 
E posteriormente a NBR 16537:2016 que institui as especificações técnicas para fabricação do projeto e instalação dos pisos táteis (ABNT, 2016).

Figura 3: Modulação do piso

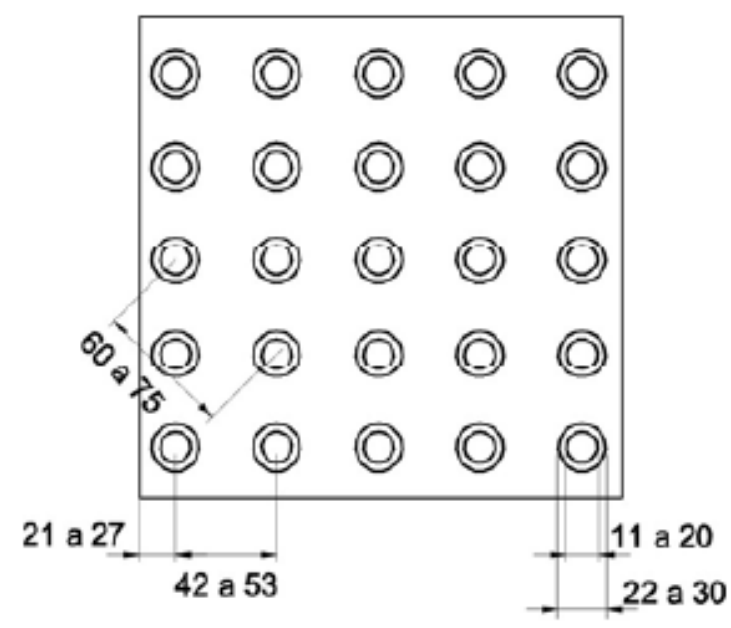

Fonte:ABNT NBR 9050:2004

A figura 3 ilustra o formato e o dimensionamento, em milímetro, do piso tátil de alerta em conformidade com a NBR 9050.

Todas as categorias de piso tátil, seja ele de alerta ou direcional, pode e são utilizados em ambientes diversos, sejam eles públicos ou privados. Segundo ALMEIDA, D. et al (2018), são variados os tipos de materiais utilizados na fabricação do piso, sendo eles borracha antiderrapante, metal ou placa cimentícia, alguns são indicados para ambientes externos, outras para internos e externos, tudo dependendo de suas características e área de aplicação.

\subsection{Projeto e desenvolvimento de produto.}

De acordo com Rozenfeld (2006), para a elaboração de um produto, se faz necessária uma associação de etapas, que tem como propósito seguir as diretrizes do projeto e processo de produção para que sua fabricação seja realizável. De olho nas necessidades do mercado, na tecnologia, que muitas vezes pode ser limitada, e no grau de competitividade do que será lançado. 
O produto desenvolvido será acompanhado desde a sua concepção até sua obsolescência, durante seu ciclo de vida, lições podem ser tomadas e estas servirão de conhecimento para o desenvolvimento ou melhoria de novos projetos (ROZENFELD, 2006).

A criação de um novo produto e a otimização do processo não é uma tarefa fácil. Para que o projeto tenha sucesso, algumas variáveis precisam ser consideradas, como dividir e detalhar as etapas do processo, elaborar instruções do produto, e o principal, investir na fase de concepção (BAXTER, 2000).

\subsection{Processo de Fabricação}

\subsubsection{Processo de conformação de matriz polimérica}

Polímeros são constituídos orgânicos com base química no carbono e hidrogênio. Sua baixa densidade os torna extremamente dúcteis e flexíveis, sendo possível a conformação destes em diversas formas complexas. Entretanto, os materiais poliméricos não respondem bem a temperaturas moderadas, podendo perder a forma. A junção de dois ou mais materiais - em geral, uma matriz e um agente de reforço - diferentes são os chamados compósitos. Essa combinação origina um novo material, que reúne as melhores características e com particularidades específicas, sendo impossível de se obter sem essa associação (CALLISTER, RETHWISCH, 2011). Segundo Groover (2016), os compósitos poliméricos são polímeros com adição de pelo menos uma fase de reforço. A adição do reforço à matriz, pode acontecer durante ou antes do processo de conformação. Em razão dessas características, a conformação de compósitos polímericos pode ser lenta e exigir a necessidade de mão de obra pesada. Isso se dá pela composição complexa de algum desses materiais, e em razão da baixa melhora na tecnologia de processamento ao longo dos anos, se comparado à de outras materias primas (GROOVER, 2016).

De acordo com Callister e Rethwisch (2011), a moldagem é um dos métodos mais utilizados na conformação de composítos poliméricos. $\mathrm{E}$ as principais técnicas de moldagem são: por compressão ou transferência, injeção, extrusão, sopro e fundição. 


\subsubsection{Molde fechado: conformação por compressão}

O molde fechado é composto por duas partes, em geral, uma móvel entra e sai durante o processo de conformação, e a cavidade, onde o material será colocado para moldagem. Esse tipo de molde, proporciona um bom acabamento nas superfícies, permite a fabricação de formas tridimensionais, além de se ter um maior controle quanto à tolerâncias do produto. A modelagem fechada é dividia em três: por compressão, transferência ou injeção (GROOVER, 2016).

Conforme Groover (2016), a conformação por compressão é um dos mais antigos e usados métodos para moldagem de compósitos poliméricos.

Figura 4:Máquina de conformação por compressão.

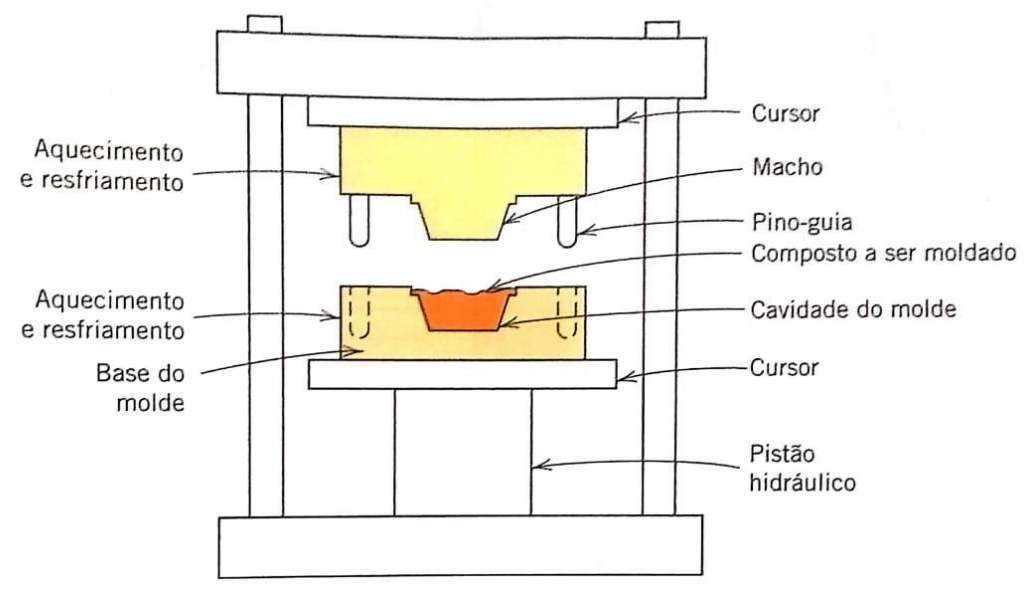

Fonte: Callister e Rethwisch (2011)

Nesse processo, a carga é inserida na cavidade e as metades do molde são unidas para comprimir a massa, dando a forma do produto.

\section{Metodologia}

O projeto é classificado como quantitativo de caráter descritivo. Nos estudos quantitativos os pesquisadores utilizam questões e hipóteses de pesquisa para moldar e focar no objetivo do estudo. As questões de pesquisas são declarações interrogativas que o investigador tenta responder. Por outro lado, as hipóteses são previsões sobre a relação entre as variáveis e são estimativas numéricas baseadas em dados coletados (CRESWELL, 2007). A análise 
descritiva possui como objetivo a descrição tanto de um fenômeno, estabelecendo relações entre as variáveis, quanto determinar a natureza dessa relação, uma de suas características mais significativas é a utilização de métodos de coleta de dados padronizados como a observação sistemática (GIL, 1946).

Segundo Iida (2005), a criação de novos produtos passa por algumas etapas de desenvolvimento:

Figura 5: Etapas do desenvolvimento de produtos,

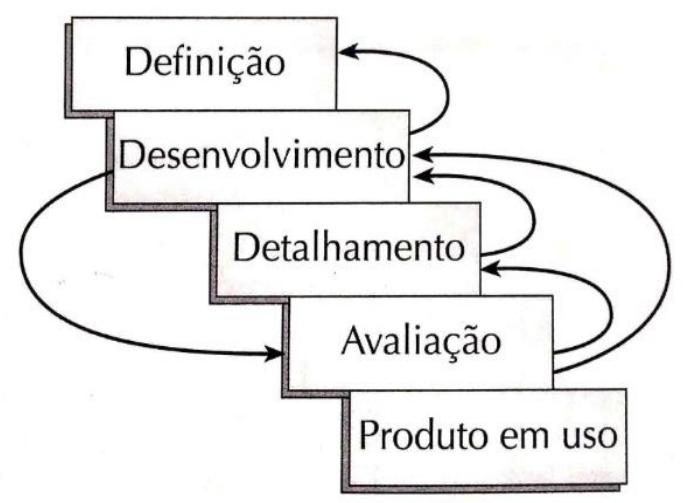

Fonte: Itiro Iida (2005)

- Definição: São examinadas as oportunidades, verificadas as demandas e definidos os objetivos do produto;

- Desenvolvimento: São analisados os requisitos do sistema, esboçado a arquitetura do sistema, geradas as alternativas de soluções e desenvolvido o sistema;

- Detalhamento: É detalhado o sistema, especificado os componentes, adaptadas as interfaces e detalhados os procedimentos de teste;

- Avaliação: É avaliado o desempenho, comparado com as especificações e feitos os ajustes necessários;

- Produto em uso: São prestados serviços pós-vendas e adquiridas experiências para outros projetos; 


\subsection{Descrição do processo de fabricação}

O produto desenvolvido é um piso tátil de alerta, feito com silicone acético de vedação e amido de farinha de milho. Para a descrição do processo de fabricação, as etapas são de acordo com Baxter (2000). Os passos foram divididos em:

1. Avaliação inicial do produto;

2. Projeto e desenvolvimento;

3. Detalhamento do processo.

Figura 6: Processo de fabricação;

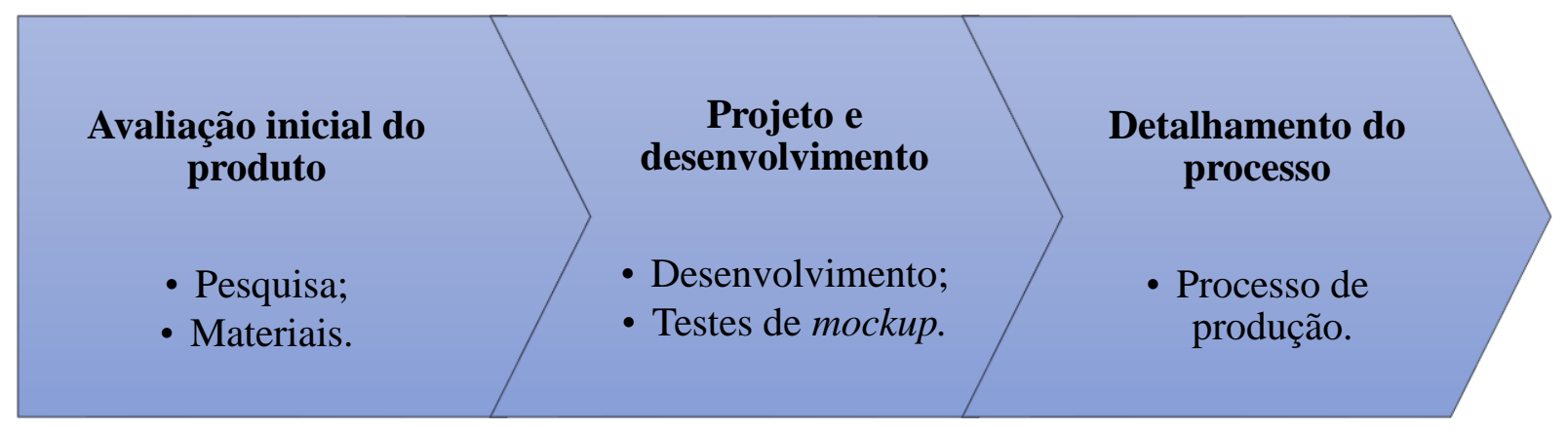

Fonte: Autoria Própria (2019)

\section{$1^{0}$ Passo - Avaliação inicial do produto:}

\section{Pesquisa:}

A fase de pesquisas se deu em visitas ao canal Paulo Biacchi, onde o mesmo ensina a fabricação da massa, além de meios alternativos para a utilização da mesma, como: decoração, reparo de objetos além de pegas antropomorfas para ferramentas.

Após a etapa de pesquisa e definição do foco do produto, segue a fase de avaliação do mesmo, onde são definidos os objetivos do projeto. Por meio das pesquisas de mercado, percebeu-se que alguns pisos táteis têm elevado preço de venda e dificultosa instalação, por exemplo, os cimentícios. 
Figura 7: O preço de um piso tátil cimentício concorrente

Piso Cimentício Rústico Borda Reta Suvial Podotátil Alerta Amarelo 20×20cm

R\$ 26,91 em 3 lojas

O Piso Cimentício Rústico Borda Reta Suvial Podotátil Alerta Amarelo 20x20cm da Cimartex é ideal para aplicação em àreas ...

Fonte: Autoria Própria (2019)

Na figura 7, é possível ver o alto custo de apenas uma peça de piso tátil cimentício. É perceptível, que essa alternativa gerará despesas altíssimas num projeto de empreendimento.

\section{Materiais:}

Nessa etapa foram feitas as pesquisas sobre a viabilidade dos materiais utilizados na fabricação, para fase de matriz foi escolhido o silicone industrial e para fase de reforço foi determinado o amido de farinha de milho. Assim como o processo de prensagem utilizado e o tipo de molde a ser empregado. Analisadas todas essas variáveis, foi acordado que o melhor método a ser usado seria o processo de fabricação por compressão por molde fechado.

Tabela 1- Materiais utilizados.

\begin{tabular}{c|cc} 
Materiais & Quantidade & Peso líq.. \\
\hline Silicone industrial & 1 und. & $230 \mathrm{~g}$ \\
Amido de Farinha de Milho & 1 und. & $500 \mathrm{~g}$
\end{tabular}

Fonte: Autoria Própria (2019)

A figura 8 , mostra a prensa utilizada na conformação do material. Composta pela cavidade, que é feita de madeira e parte móvel, feita de plástico, sendo essa responsável por dar a textura ao piso. 
Figura 8- Prensa de molde fechado utilizada para produzir o piso tátil

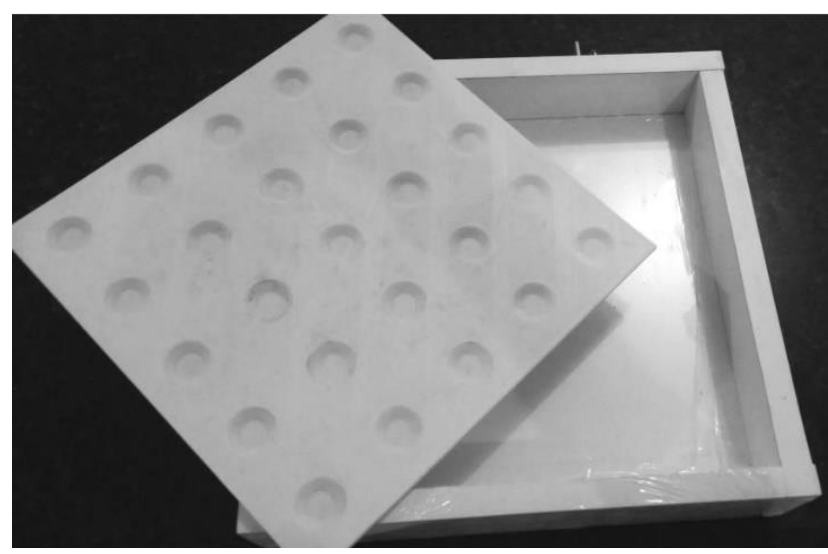

Fonte: Autoria Própria (2019)

\section{$2^{\circ}$ Passo - Projeto e desenvolvimento:}

Nas etapas iniciais do desenvolvimento, foram fabricados os primeiros pisos em tamanho reduzido, 10x10 $\mathrm{cm}$. Com base nessas primeiras amostras, foi possível mensurar as quantidades de insumo na formulação da massa e como ficaria o acabamento da peça após o processo de conformação.

Figura 9: Os mockups do produto

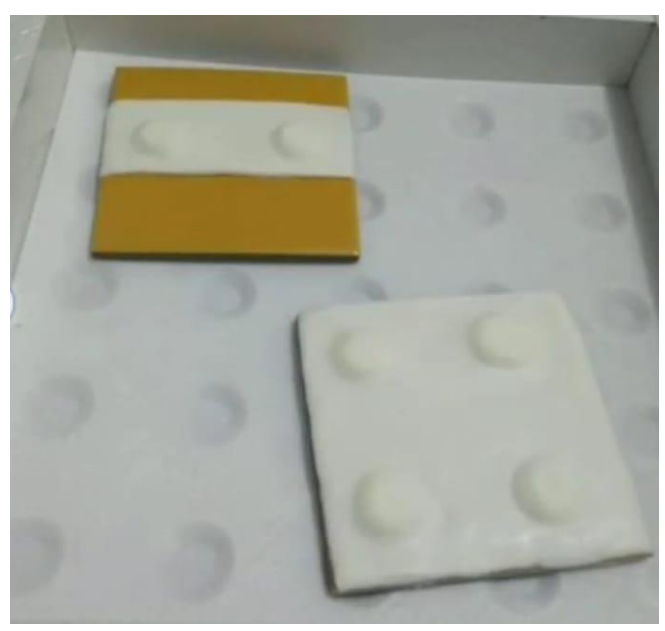

Fonte: Autoria Própria (2019)

Depois da fabricação dos protótipos, foram feitas as análises das modificações que seriam necessárias para o projeto final. Por fim, a peça conforme a NBR 9050:2004 de tamanho $25 \times 25 \mathrm{~cm}$. 
Figura 10: Peça dentro da cavidade

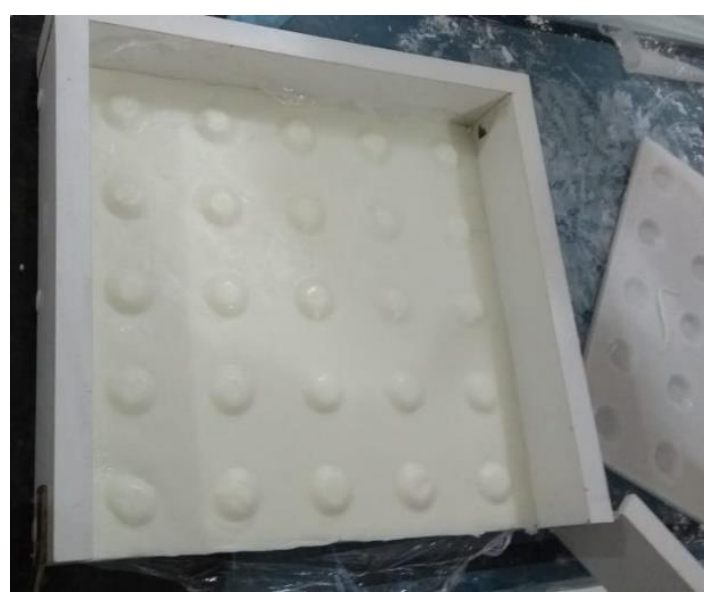

Fonte: Autoria Própria (2019)

\section{$3^{\circ}$ Passo - Detalhamento do processo:}

1) Para a construção da peça de $25 \times 25 \mathrm{~cm}$ foram necessários $110 \mathrm{~g}$ de amido de farinha de milho e $148 \mathrm{~g}$ de silicone industrial;

2) O amido e silicone foram misturados até formar uma massa maleável e homogênea;

3) O molde foi coberto com papel filme e untado com vaselina e maisena (amido de farinha de milho);

4) A massa foi aberta e posta no molde;

5) A massa é prensada com a parte móvel do molde até que a massa adquira os aspectos da fôrma;

6) O piso tátil é removido da cavidade.

\section{Resultado e Discussões}

O projeto teve como objetivo apresentar uma alternativa aos materiais de fabricação para piso táteis, com enfoque no piso podotátil de alerta por sobreposição. O produto foi desenvolvido atendendo as normas da NBR 9050:2004, utilizando materiais alternativos o produto foi desenvolvido para apresentar as mesmas propriedades de um piso tátil de borracha, só que com um custo benefício superior.

Os materiais utilizados no processo de fabricação são acessíveis, além de possuírem baixo custo. A massa homogênea que é gerada a partir da mistura de silicone e amido de milho, é colocada na prensa de molde fechado e depois da compressão, a peça conformada é 
retirada. Após processo de cura da mistura, que tem duração de 24 horas, se tem o produto final resistente, flexível e dúctil.

Figura 11: Conformação da massa.

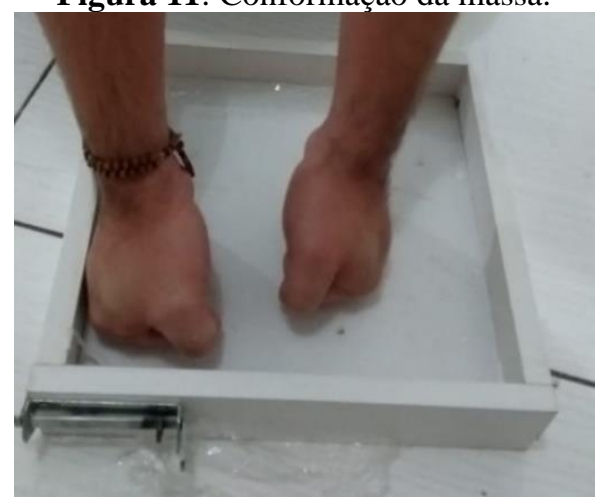

Fonte: Autoria Própria (2019)

Os testes iniciais foram feitos em escala reduzida de $10 \times 10 \mathrm{~cm}$, suas propriedades foram testadas, sendo elas: durabilidade, resistência a deformação e flexibilidade. Os primeiros testes foram feitos levando em consideração a aceitação da deformação sob o peso das pessoas que circulam sobre piso tátil, três pessoas com pesos diferentes circularam, pularam e chutaram em cima do piso. A figura 12 mostra os testes realizados no mockups.

Figuras12: Antes da realização dos testes (a) e após as realizações dos testes no mockups (b).

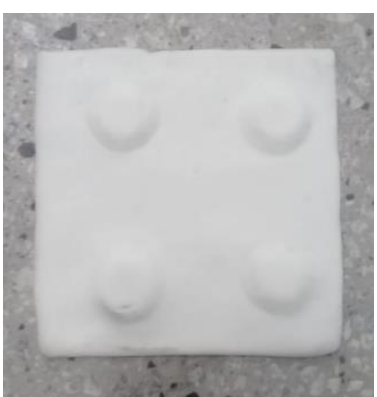

(a)

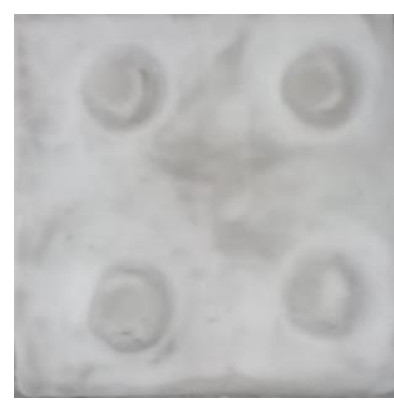

(b)

Fonte: Autoria Própria (2019).

Após a realização dos testes, foi possível observar que o produto atendia as propriedades previstas. Durante o processo de fabricação, foram realizadas as pesagens dos insumos. Para a produção de uma peça $25 \times 25 \mathrm{~cm}$, foram necessárias as seguintes quantidades de insumos: 
Tabela 2: Insumos necessários para produzir uma peça $25 \times 25 \mathrm{~cm}$

\begin{tabular}{c|c} 
Materiais & Quantidade \\
\hline $\begin{array}{c}\text { Silicone industrial } \\
\text { Amido de Farinha de Milho }\end{array}$ & $148 \mathrm{~g}$ \\
Fonte: Autoria Própria (2019)
\end{tabular}

Em seguida, foram efetuados os cálculos para verificação da viabilidade econômica do produto. Comparando os preços com os concorrentes, foi percebido que o preço da peça cimentícia é de $\mathrm{R} \$ 26,91$ em três concorrentes, e o preço do piso de borracha é em média $\mathrm{R} \$ 15,55$. Levando em consideração as informações anteriores, o valor unitário do produto final é de aproximadamente $\mathrm{R} \$ 10,40$.

É necessário enfatizar, que a técnica de fabricação utilizada é manual e em baixa escala, em razão disso, há uma taxa elevada de retrabalho e desperdício de matéria-prima durante a confecção. Entretanto, se houvesse uma produção em massa e fossem empregados maquinários que auxiliassem a manufatura, o custo por unidade da peça seria minimizado, não esquecendo do desperdício dos materiais e do retrabalho

Figura 13: Piso Tátil

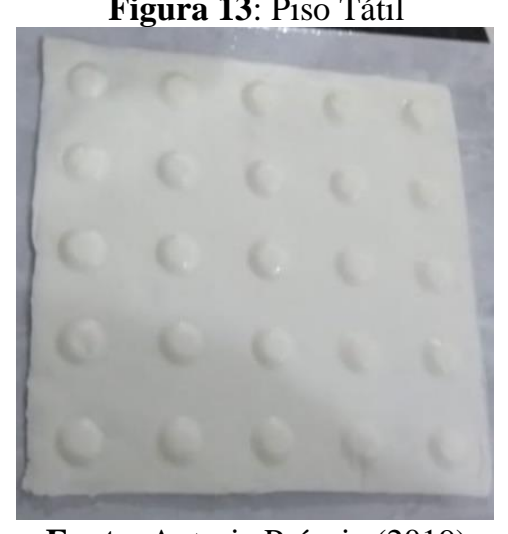

Fonte: Autoria Própria (2019)

\section{Considerações Finais}

O estudo teve como objetivo, apresentar uma alternativa aos materiais de fabricação de piso táteis presentes no mercado, com matéria-prima acessível e de baixo custo.

Ao final, o produto atendeu a norma técnica. Durante o desenvolvimento do projeto, o custo de fabricação obtido foi de $\mathrm{R} \$ 10,40$, sendo inferior ao preço de venda dos concorrentes, atestando assim a sua viabilidade econômica. Portanto, além de obter baixo 
custo de confecção, pode ser replicado em larga escala com a utilização de maquinários, sendo uma alternativa viável para a comercialização de piso tátil.

\section{Referências}

ALMEIDA, D. et al. XXXVIII ENCONTRO NACIONAL DE ENGENHARIA DE PRODUCÃOENEGEP. ANÁLISE DE MATERIAIS RECICLÁVEIS PARA APLICAÇÃO EM PISOS TÁTEIS,

Maceió, $\quad 16 \quad$ a 19 Outubro 2018. 1-12. Disponivel em: 〈http://www.abepro.org.br/biblioteca/TN_STO_261_502_36042.pdf>. Acesso em: 20 Jun. 2019.

ALMEIDA, Eridiana Pizzinatto; GIACOMINI, Larissa Bressan; BORTOLUZZI, Marluse Guedes. Mobilidade e Acessibilidade Urbana. Seminário Nacional de Construções, Passo Fundo- RS. 2013. Acesso em: 21 jun.2019.

ASSOCIAÇÃO BRASILEIRA DE NORMAS TÉCNICAS. NBR 9050:2004. ABNT. Rio de Janeiro, p. 1105. 2004.

ASSOCIAÇÃO BRASILEIRA DE NORMAS TÉCNICAS. NBR 9050: Acessibilidade a edificações, mobiliário, espaços e equipamentos urbanos. 3 ed. Rio de Janeiro, 2015.

ASSOCIAÇÃO BRASILEIRA DE NORMAS TÉCNICAS. NBBR 16537:2016. ABNT. Rio de Janeiro, p. 1-44. 2016.

BAXTER, M. R. Projeto de produto: guia prático para o design de novos produtos. Tradução de Itiro IIDA. $\quad 2^{\text {a }}$ ed. São Paulo: Blucher, 2000. Disponível em: <https://www.academia.edu/8458186/Projeto_de_Produto_Guia_pr_Atico_para_o_design_de_novos_pro dutos_Mike_Baxter_compartilhandodesign_wordpress_com>. Acesso em: 24 jun.2019.

BIACHI, Paulo. COMO FAZER UMA MASSA COLORIDA FLEXÍVEL | DIY LIFE HACKS. 2018. Disponível em: 〈https://www.youtube.com/watch?v=Cpq3Hd 64OrU〉. Acesso em: 22 jun. 2019.

BIACHI, Paulo. Como consertar CABO de IPHONE com MAIZENA \#DIY. 2016. Disponível em: <https://www.youtube.com/watch?v=x6yjVtaAdtU〉. Acesso em: 06 abril 2019. 
BITTENCOURT, Ana Lúcia C.; MIRANDA, VMD; SOUSA, SMV. Acessibilidade em calçadas: modelo para verificação em projetos básicos de editais de obras e serviços de Engenharia pelos Tribunais de

Contas. Pós-graduação em Engenharia Civil, Pontifícia Universidade Católica do Rio de Janeiro, Rio de Janeiro, 2008.

CALLISTER, W. D.; RETHWISCH, D. G. Ciência e engenharia de materiais: uma introdução. Tradução de Sergio M S Soares. 8a . ed. Rio Janeiro: LTC, 2012. 1-817 p.

CRESWELL, John W., Projeto de Pesquisa: Métodos qualitativos, quantitativos e misto. $2^{\mathrm{a}}$ edição Porto Alegre: Artmed, 2007.

DISCHINGER, Marta; BINS ELY, Vera Helena Moro. A importância dos processos perceptivos na cognição de espaços urbanos para portadores de deficiência visual. IX CONGRESSO BRASILEIRO DE ERGONOMIA, Salvador, 1999. p 1-8.

GIL, Antônio Carlos, Como Elaborar Projetos de Pesquisa. 4ª edição - São Paulo: Atlas, 2002.

GROOVER, M. P. Introdução aos processos de fabricação. Tradução de Anna C Araujo e André R Oliveira. $1^{\mathrm{a}}$. ed. Rio de Janeiro: LTC, 2016. 1-737 p.

IIDA, I. Ergonomia: Projeto e produção. 2a . ed. São Paulo: Blucher, 2005.

INSTITUTO BRASILEIRO DE GEOGRAFIA E ESTATÍSTICA - IBGE. Características gerais da população: religião e pessoa com deficiência. IBGE. Rio de Janeiro, p. 1-215. 2010.

MÁSCULO, F. S.; VIDAL, M. C. Ergonomia: Trabalho adequado e eficiente. Rio de Janeiro: Elsevier, 2011. 394-419 p.

MOZAIK. Blog. Pisos táteis ou podotáteis? Qual o termo certo? Como são classificados. Publicado em 16 de junho de 2010. Disponível em: <http://mozaik.com.r/blog/2010/06/16/pisos-tateis-ou-podotateisqual-o-termo-certo-como-sao-classificados/>. Acesso em: 22 jun. 2019. 
NORMANN, Atenante Ferreira Meyer. ACESSIBILIDADE: Os desafios ergonômicos à aplicação das normas de proteção do trabalho de pessoas portadoras de deficiência - PPD's. 2004. 154 f. Dissertação (Mestrado Profissional em Engenharia de Produção) - Universidade Federal do Rio Grande do Sul, Porto Alegre, 2004.

PROJEMAK: soluções em acessibilidade. Projemak, 2016. Disponivel em: <http://projemak.com.br/oque-e-a-norma-nbr-9050/>. Acesso em: 20 jun. 2019.

ROZENFELD, H. et al. Gestão de Desenvolvimento de Produtos: uma referência para melhoria de processo. São Paulo: Saraiva, $2006 . \quad$ Disponivel em: $<$ https://www.ebah.com.br/content/ABAAAeuDgAB/gestao-desenvolvimento-produtos-referencia melhoria-processos\# >. Acesso em: 24 Junho 2019.

SILVA, Marcos Vinicius Leite da et al. DESENVOLVIMENTO DE PRENSA PARA PISOS PODOTÁTEIS. In: Anais do VI Simpósio de Engenharia de Produção - SIMEP 2018. Anais. Salvador (BA) UNIFACS, 2018. Disponível em: <https//www.even3.com.br/anais/6simep/79428DESENVOLVIMENTO-DE-PRENSA-PARA-PISOS-PODOTATEIS〉. Acesso em: 22 junho 2019. 